\title{
Similarities and Differences between Flow Boiling in Microchannels and Pool Boiling
}

\author{
Satish G. KANDLIKAR \\ Mechanical Engineering Department, \\ Rochester Institute of Technology, Rochester, NY, USA \\ Email: sgkeme@rit.edu
}

\begin{abstract}
Recent literature indicates that under certain conditions the heat transfer coefficient during flow boiling in microchannels is quite similar to that under pool boiling conditions. This is rather unexpected as microchannels are believed to provide significant heat transfer enhancement under single-phase as well as flow boiling conditions. This paper explores the underlying heat transfer mechanisms and illustrates the similarities and differences between the two processes. Formation of elongated bubbles and their passage over the microchannel walls have similarities to the bubble ebullition cycle in pool boiling. During the passage of elongated bubbles, the longer duration between two successive liquid slugs leads to wall dryout and a critical heat flux that may be lower than that under pool boiling conditions. A clear understanding of the similarities and differences will help in overcoming some of these limiting factors and in developing strategies for enhancing heat transfer during flow boiling in microchannels.
\end{abstract}

Keywords: Microlayer, Elongated Bubbles, Pool Boiling, Flow Boiling, Microchannels

\section{Introduction}

The nucleation criterion developed by Hsu (1962) has been successful in predicting the onset of nucleation in pool boiling as well as in flow boiling in conventional sized channels. The criterion was also shown to be quite accurate for flow boiling in microchannels by a number of investigators, including Zhang, et al. (2005) and Kandlikar et al. (2006). The high single phase heat transfer coefficient value prior to nucleation in flow boiling leads to nucleation cavity diameters that are smaller than those in pool boiling. This link between pool boiling and flow boiling is an important factor in comparing the two boiling modes.

In the quest of improved heat removal rates, in general, pool boiling is considered to be more efficient (higher heat transfer coefficient) than single phase liquid flow, while flow boiling provides the highest heat transfer coefficients. However, recent data obtained with enhanced single-phase flow and flow boiling in microchannels indicate that this may not be necessarily true with the current status of these two modes of heat transfer.
Table 1 - Comparison of heat transfer coefficients with water under different modes.

\begin{tabular}{|c|c|c|}
\hline Heat transfer mode & $\begin{array}{c}\mathrm{h}, \\
\mathrm{kW} / \mathrm{m}^{2 \circ} \mathrm{C}\end{array}$ & $\begin{array}{c}\mathbf{q}, \\
\mathbf{M W} / \mathbf{m}^{2}\end{array}$ \\
\hline $\begin{array}{l}\text { Single-phase in plain } 100- \\
200 \quad \mu \mathrm{m} \\
\text { microchannels, }\end{array}$ & $10-15$ & $0.1-0.2$ \\
\hline $\begin{array}{l}\text { Single-phase in enhanced } \\
\text { microchannels, } 48 \mu \mathrm{m} \times 256 \\
\mu \mathrm{m} \text {, offset strip fins, } 500 \\
\mu \mathrm{m} \text {, Colgan et al. }(2007) \text {, } \\
\text { Steinke and Kandlikar } \\
(2006)\end{array}$ & $>500$ & $5-10$ \\
\hline $\begin{array}{l}\text { Pool boiling, flat surface, } \\
\text { fully developed boiling, } \\
\text { Nukiyama } \\
\text { microdrilled surface (1934), } \\
\text { al., 2007) }\end{array}$ & $\sim 30-300$ & $1.2-4.8$ \\
\hline $\begin{array}{l}\text { Saturated flow boiling in } \\
\mathrm{D}_{\mathrm{h}} \sim 207 \mu \mathrm{m} \text { rectangular } \\
\text { microchannels, Steinke and } \\
\text { Kandlikar }(2004), \quad \text { with } \\
\text { reentrant cavities Kuo and } \\
\text { Peles (2007) }\end{array}$ & $30-80$ & $2-3.5$ \\
\hline
\end{tabular}

Table 1 shows a comparison of heat transfer coefficients and heat fluxes for four cases single-phase flow in plain microchannels, 
single-phase flow in enhanced microchannels, pool boiling, and saturated flow boiling in plain and enhanced (with reentrant cavities) microchannels. These values are obtained in chip cooling application with laminar flow in microchannels and a pressure drop that is less than a few bars to make the system practical. The single-phase value is obtained from laminar flow theory (considering entrance length region). The plain microchannels are unable to meet the high heat flux cooling requirement of $1000 \mathrm{~W} / \mathrm{cm}^{2}\left(10 \mathrm{MW} / \mathrm{m}^{2}\right)$. However, the microchannels enhanced with short offset strip fins provide a very high heat transfer coefficient. In a practical system with this geometry, Colgan et al. (2007) employed multiple inlet/outlet regions with a flow length of only $2 \mathrm{~mm}$ through the microchannels. This configuration holds the most promise in meeting the future chip cooling challenges.

The pool boiling mode at macroscale offers an efficient mode of heat transfer. The saturated flow boiling heat transfer with plain microchannels (Steinke and Kandlikar, 2004) and with reentrant cavities (Kuo and Peles, 2007) both provide an improvement over plain microchannels, but fall substantially below the desired values. Although these values are higher than those under pool boiling, the increase is not significant. In fact, employing enhanced pool boiling surfaces can improve the performance by a factor of 2-4 (e.g., microdrilling the heater surface with holes placed at 5-10 mm pitch, Das et al., 2007).

In comparison, a set of parallel microchannels with or without reentrant cavities yields much lower performance as compared to single-phase flow in enhanced microchannels or pool boiling on enhanced surfaces. This has been a major concern in developing flow boiling systems to meet the needs in electronic cooling applications.

There have been a number of papers published exploring the effect of diameter on flow boiling heat transfer. A comparison of two data sets obtained by Kenning and Cooper (1988) for a $9.6 \mathrm{~mm}$ diameter circular tube and by Steinke and Kandlikar for a $207 \mu \mathrm{m}$ hydraulic diameter rectangular channel is shown in Fig. 1. Both data sets are obtained at close to atmospheric pressure and the Boiling numbers are around $1.5 \times 10^{-4}$ in both cases. The effect of diameter on the ratio of twophase to liquid only single-phase heat transfer coefficients is depicted in Fig. 1. It is seen that this ratio is reduced considerably from a value of 9.5 for the $9.6 \mathrm{~mm}$ diameter tube to 4 for the $207 \mu \mathrm{m}$ channel. Further, considering the fact that $h_{\mathrm{LO}}$ in microchannel corresponds to laminar flow conditions, a compelling argument can be made for the dramatic reduction in heat transfer coefficient for the smaller diameter tube.

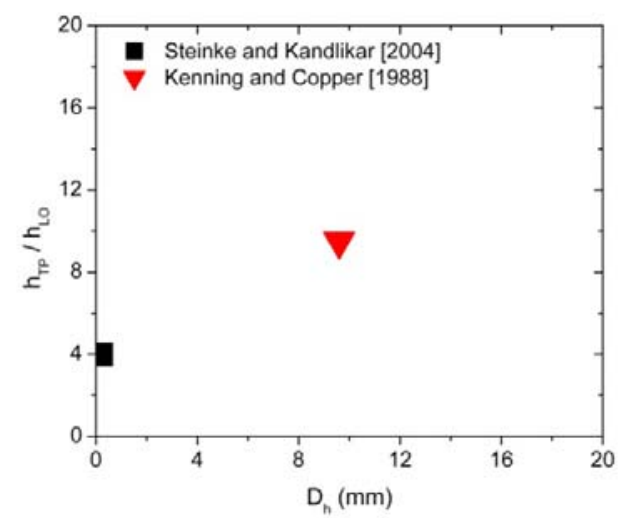

Fig. 1 Effect of channel hydraulic diameter on the ratio $\mathrm{h}_{\mathrm{TP}} / \mathrm{h}_{\mathrm{LO}}$ for $\mathrm{Bo} \approx 1.5 \times 10^{-4}$ during flow boiling of water near atmospheric pressure.

It has been suggested by a number of authors, including Lazarek and Black (1982), that flow boiling in narrow channels can be predicted reasonably well with a pool boiling correlation. Kew and Cornwell (1997) compared the flow boiling data in narrow channels with an established pool boiling correlation by Cooper (1984) with some degree of success. The other correlations that were successfully tried had heat flux as the primary variable. This realization, brought about by the success of the pool boiling correlations to predict the flow boiling in microchannels, is really the precursor to the present paper. This similarity is further explored using the available literature on experimental data and theoretical models. The discussion is focused on water as the working fluid, but by no means is this study intended to be restrictive in this regard. The broad availability of experimental data with water 
makes it possible to present a more comprehensive comparison between the pool boiling and microchannel flow boiling.

\section{Nucleate Boiling and Convective Boiling Contributions}

The contributions from nucleate boiling and convective boiling during flow boiling are well recognized. The nucleate boiling contribution is dependent on the heat flux, in a manner similar to the pool boiling with an exponent of around 0.7 . The convective boiling component is independent of the heat flux and varies with the mass flux. For the conventional large diameter tubes, the mass flux dependence was identified with an exponent of 0.8 , which is in agreement with the turbulent single-phase flow relationship. A flow boiling map proposed by Kandlikar (1991) showed these contributions with Boiling number Bo and density ratio, $\rho_{\mathrm{L}} / \rho_{\mathrm{G}}$, as parameters. The map was developed with $h_{\mathrm{TP}} / h_{\mathrm{LO}}$ versus $x$ using the Kandlikar (1990) correlation. The map was instrumental in explaining the different dependencies observed in the two-phase heat transfer data as a function of quality. The nucleate boiling component is adversely affected with an increase in quality, while the convective boiling term increases with quality due to the higher specific volume of vapor being produced. The relative contributions from these components are governed by Bo and $\rho_{\mathrm{L}} / \rho_{\mathrm{G}}$. A higher density ratio causes a larger increase in the overall flow velocity upon vaporization, leading to a greater increase in the heat transfer coefficient, while a low value of density ratio causes the convective contribution to increase only moderately. A combination of low Bo and high $\rho_{\mathrm{L}} / \rho_{\mathrm{G}}$ causes $h_{\mathrm{TP}} / h_{\mathrm{LO}}$ to increase with an increase in $x$ while a high Bo and low $\rho_{\mathrm{L}} / \rho_{\mathrm{G}}$ causes $\mathrm{h}_{\mathrm{TP}} / \mathrm{h}_{\mathrm{LO}}$ to decrease with an increase in $x$.

These trends, described by Kandlikar (1991), are further affected by laminar flow occurring in small diameter channels. Depending on the single-phase liquid Reynolds number, the flow may be in the laminar region, where the single-phase liquid heat transfer coefficient under fully developed flow conditions is independent of the mass flux. This is one of the reasons why the twophase heat transfer coefficient is dramatically altered in microscale channels.

Another effect of the small channel dimensions arises due to the changes occurring in the flow patterns. The nucleating vapor bubbles are confined in the small channels and grow as elongated bubbles, forming alternate liquid slugs and elongated bubbles. The twophase flow structures during flow boiling resemble the respective pool boiling characteristics as shown in Table 2 .

Table 2 Comparison of two-phase flow structures in the two boiling modes

\begin{tabular}{|l|l|}
\hline \multicolumn{1}{|c|}{ Flow Boiling } & \multicolumn{1}{|c|}{ Pool Boiling } \\
\hline $\begin{array}{l}\text { Bubble inception as } \\
\text { the nucleation criterion } \\
\text { is met for specific } \\
\text { cavities under single- } \\
\text { phase liquid flow. }\end{array}$ & $\begin{array}{l}\text { Bubble inception as the } \\
\text { nucleation criterion is } \\
\text { met for specific cavities } \\
\text { under natural convection } \\
\text { with liquid. }\end{array}$ \\
\hline $\begin{array}{l}\text { Elongated bubble } \\
\text { covering the channel } \\
\text { walls. }\end{array}$ & $\begin{array}{l}\text { Growing bubles } \\
\text { covering the heater } \\
\text { surface. }\end{array}$ \\
\hline $\begin{array}{l}\text { Liquid slug being } \\
\text { pushed between the } \\
\text { two consecutive } \\
\text { elongated bubbles. }\end{array}$ & $\begin{array}{l}\text { Liquid circulation around } \\
\text { the nucleating bubbles as } \\
\text { a result of the individual } \\
\text { bubble ebullition cycles. }\end{array}$ \\
\hline $\begin{array}{l}\text { Liquid slugs are } \\
\text { intensely mixed with } \\
\text { vapor in a churn flow. }\end{array}$ & $\begin{array}{l}\text { Liquid bubbles (undergoing } \\
\text { ebullition cycles) is } \\
\text { intensely mixed with } \\
\text { vapor at high heat fluxes } \\
\text { under fully developed } \\
\text { boiling conditions. }\end{array}$ \\
\hline
\end{tabular}

The single-phase heat transfer in microchannels is generally under laminar flow conditions due to the pressure drop limitations and the small channel dimensions. As pointed out earlier, the convective contribution from the single-phase liquid flow needs to be considered using the laminar flow equation. The dependence of the convective contribution is thus altered from the conventional channel trends since the Nusselt number in laminar flow is independent of the flow rate. These effects are accounted for in the flow boiling correlation proposed by Kandlikar and Balasubramanian (2005). These equations are rewritten in terms of the density ratio and 
Boiling number as follows:

For $400 \leq \operatorname{Re}_{\mathrm{LO}} \leq 1600$

$\frac{h_{T P}}{h_{L O}}=$ larger of $\left\{\begin{array}{c}\frac{h_{T P, N B D}}{h_{L O}} \\ \frac{h_{T P, C B D}}{h_{L O}}\end{array}\right\}$

where

$\frac{h_{T P, N B D}}{h_{L O}}=0.6683\left(\rho_{L} / \rho_{G}\right)^{0.1} x^{0.16}(1-x)^{0.64}$
$+1058.0 B o^{0.7}(1-x)^{0.8} F_{F l}$

$$
\begin{array}{r}
\frac{h_{T P, C B D}}{h_{L O}}=1.136\left(\rho_{L} / \rho_{G}\right)^{0.45} x^{0.72}(1-x)^{0.0 .08} \\
+667.2 B o^{0.7}(1-x)^{0.8} F_{F l}
\end{array}
$$

The single-phase heat transfer coefficient $h_{\mathrm{LO}}$ is calculated from the laminar flow equation instead of the Gnielinski correlation for the turbulent region. In the region of $\mathrm{Re}$ from 1600 to 3000 , a linear interpolation is recommended.

For the low Reynolds number range $100 \leq \operatorname{Re}_{\mathrm{LO}}<400$, the heat transfer coefficient is found to be always nucleate boiling dominant (NBD). Thus:

$$
\begin{aligned}
\frac{h_{T P}}{h_{L O}}= & \frac{h_{T P, N B D}}{h_{L O}} \\
= & 0.6683\left(\rho_{L} / \rho_{G}\right)^{0.1} x^{0.16}(1-x)^{0.64} \\
& \quad+1058.0 B o^{0.7}(1-x)^{0.8} F_{F l}
\end{aligned}
$$

In the range $\mathrm{Re}<100$, the convective component in the above NBD term is reduced further and $h_{\mathrm{TP}}$ depends on the nucleate boiling component alone:

$\frac{h_{T P}}{h_{L O}}=1058.0 B o^{0.7}(1-x)^{0.8} F_{F l}$

Equations (1)-(5) are used to generate a flow boiling map for microchannels. Three values of density ratio of 10,100 and 1000 , and two value of $\mathrm{Bo}^{*}, 10^{-4}$ and $10^{-3}$ are used to generate the plots. The modified Boiling number $\mathrm{Bo}^{*}$ is defined as follows:

$B o^{*}=B o \times\left(F_{F l}\right)^{1 / 0.7}$

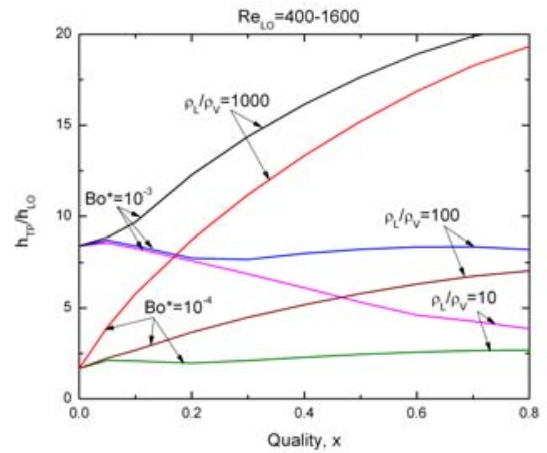

Fig. 2 Flow boiling map for microchannels in the range $400 \leq \operatorname{Re}_{\mathrm{LO}} \leq 1600, B o^{*}=B o \times\left(F_{F l}\right)^{1 / 0.7}$

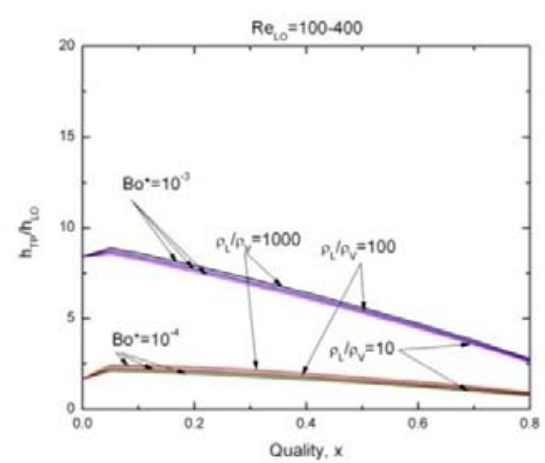

Fig. 3 Flow boiling map for microchannels in the range $100 \leq \operatorname{Re}_{\mathrm{LO}}<400, B o^{*}=B o \times\left(F_{F l}\right)^{1 / 0.7}$

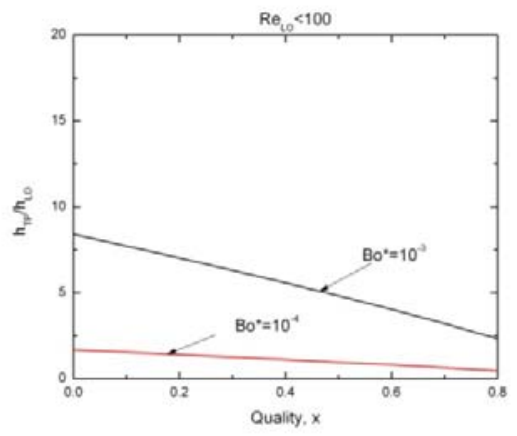

Fig. 4 Flow boiling map for microchannels in the range $\mathrm{Re}_{\mathrm{LO}}<100, B o^{*}=B o \times\left(F_{F l}\right)^{1 / 0.7}$

Figures 2-4 show the plots generated for different $\mathrm{Re}$ ranges. Figure 2 shows the variation of $h_{\mathrm{TP}} / h_{\mathrm{LO}}$ with $x$ with different values of Bo for $400 \leq \operatorname{Re}_{\mathrm{LO}} \leq 1600$. This plot is same as that for large diameter tubes, but the actual heat transfer coefficient will be different since the single-phase coefficient $h_{\mathrm{LO}}$ will be derived from the laminar flow equations.

Figure 3 shows the flow boiling map for $100 \leq \mathrm{Re}_{\mathrm{LO}}<400$. Here the nucleat(5)boiling 
component begins to play a major role as seen by the continuous decrease in $h$ with $\mathrm{x}$ throughout the range. In other words, the increased flow velocity at higher $x$ does not provide the expected benefits in terms of improved convective heat transfer.

Figure 4 shows the flow boiling map for very low values of $\mathrm{Re}_{\mathrm{LO}}<100$. The convective component is completely blocked off; the density ratio has no effect on $h$. Here the suppression effects are overriding and the heat transfer exhibits similar characteristics as in nucleate boiling with the increased suppression effects at higher qualities.

\section{Heat Transfer Processes during Pool and Flow Boiling}

\subsection{Factors Responsible for Heat Transfer Degradation in Microchannels}

The flow boiling maps depicted in Figs. 2-4 are based on the experimental data and provide a visual tool to illustrate the effects of flow parameters on heat transfer coefficient. As the $\mathrm{Re}_{\mathrm{LO}}$ is reduced, it is seen that the nucleate boiling becomes the dominant mode, with its decreasing trend in $h$ versus $x$. Further decreases in Reynolds number causes the heat transfer to deteriorate, with the elimination of the convective contribution term in Eq. (5).

The boiling instabilities experienced in microchannels are another major cause for heat transfer reduction. These instabilities occur at lower mass fluxes as the inertia of the incoming liquid is insufficient to prevent the liquid from rushing back. The reasons for instabilities and methods for preventing them have been discussed in a number of publications, including Serizawa et al. (2002), Steinke and Kandlikar (2004), Hetsroni et al. (2005), Kandlikar et al. (2006), and Kuo and Peles (2008). As a result of the instabilities, the walls of the microchannels remain exposed to the expanding vapor bubble, creating local dry patches on the wall and causing the heat transfer deterioration.

Another method to avoid the instabilities is to change the operating conditions with increased mass fluxes. Dong et al. (2008) conducted experiments with R-141b in $60 \mu \mathrm{m}$ $\times 200 \mu \mathrm{m}$ parallel rectangular microchannels for mass fluxes of 400 to $980 \mathrm{~kg} / \mathrm{m}^{2}$ s. Boiling was initiated within the channels with subcooled liquid inlet. Pressure drop oscillations were not observed and stable boiling was attained. The stable results obtained under such conditions were shown to agree quite well with the Kandlikar and Balasubramanian (2004) correlation, whereas the unstable data observed in the Steinke and Kandlikar correlation showed a marked deterioration with increasing quality as shown in Fig. 5. The results of Dong et al. (2008) are shown in Fig. 6. Although a higher mass flux is beneficial for heat transfer, the resulting pressure drop could be prohibitively large.

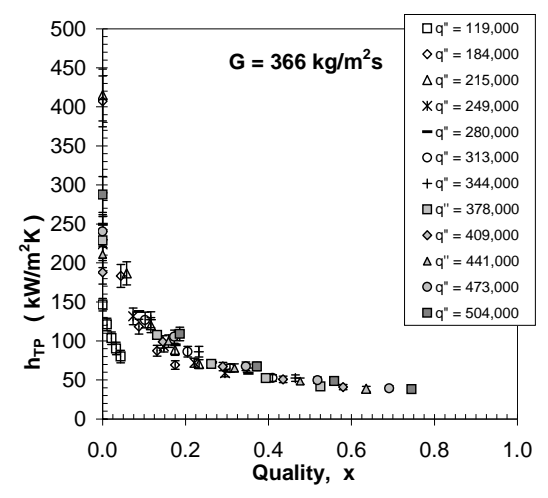

Fig. 5 Flow boiling results from Steinke and Kandlikar (2004) for water showing dramatic reduction in heat transfer performance at increased qualities due to instabilities. q" heat flux, $\mathrm{W} / \mathrm{m}^{2}$.

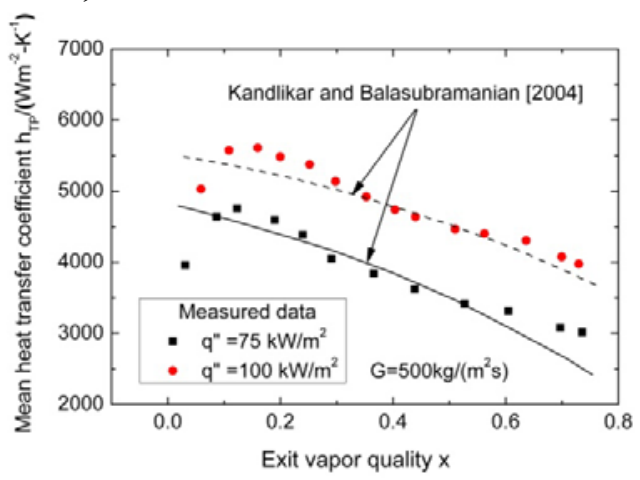

Fig. 6 Experimental data for flow boiling of R$141 \mathrm{~b}$ by Dong et al. (2008) and predictions from Kandlikar and Balasubramanian (2004) at $\mathrm{G}=500 \mathrm{~kg} / \mathrm{m}^{2} \mathrm{~s}$ under stable operation, $\mathrm{F}_{\mathrm{Fl}}=1.8, \quad B 0^{*}=\left[\mathrm{q} /\left(\mathrm{Gh}_{\mathrm{fg}}\right)\right] \times \mathrm{F}_{\mathrm{Fl}}=1.2 \times 10^{-3} \quad$ (lower line) and $1.6 \times 10^{-3}$ (upper line). 


\subsection{Similarities between Pool Boiling and Microchannel Flow Boiling Processes}

Some of the recent publications provide an insight into the reasons for this dramatic reduction in $\mathrm{h}$ with $x$, even under stable conditions. Using the elongated bubble flow pattern description, Kandlikar (2009a) pointed out the similarities between the microchannel flow boiling and pool boiling heat transfer. As a bubble grows, the downstream interface represents the receding liquid-vapor interface of a growing nucleating bubble, whereas the upstream interface of the elongated bubble is similar to the advancing liquid-vapor interface of a nucleating bubble as its base shrinks and the bubble begins to depart from the heated surface in pool boiling. Figure 7 depicts the respective interfaces as elongated bubbles are formed in a microchannel. These two interfaces were experimentally studied in a moving meniscus on a heated surface by Kandlikar et al. (2005) and numerically by Mukherjee and Kandlikar (2006). Their studies showed the important roles played by transient conduction as the liquid interface advances over the heater surface. The microconvection caused by the liquid flow behind the advancing liquid interface for a moving meniscus is shown in Fig. 7(b), and during a nucleate boiling bubble ebullition cycle is shown in Fig. 7(c). The receding interface provides a phase change surface where the liquid superheat is dissipated and cooled liquid becomes available for the transient conduction process. The advancing and receding interfaces seen around an elongated bubble are shown in Fig. 7(a).

In the model proposed by Jacobi and Thome (2002), the heat transfer in the liquid slug region is assumed to be by laminar steady-state convection, and its contribution is quite small compared to that from microlayer evaporation. However, the numerical simulation and the results from transient conduction model described by Mukherjee and Kandlikar (2006) and Kandlikar et al. (2005) indicate that transient conduction and microconvection modes contribute significantly in the evaporating meniscus geometry.

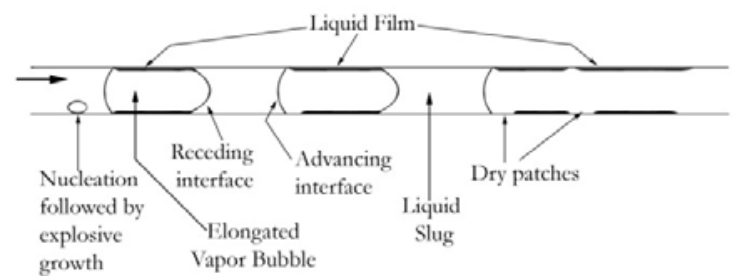

(a)

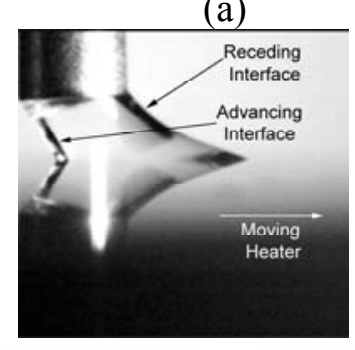

(b)

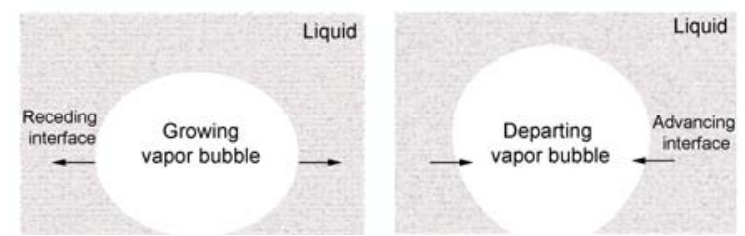

(c)

Fig. 7 Elongated bubbles in microchannels presenting advancing and receding interfaces in (a) that are similar to interface movements of a moving meniscus (b) and a nucleating bubble during a bubble ebullition cycle in pool boiling shown in (c).

Mukherjee and Kandlikar (2005) simulated the bubble growth in microchannels and concluded that the transient conduction and the subsequent convection behind the evaporating liquid-vapor interface were the major contributors to the total heat transfer process in microchannel flow boiling as well.

\subsection{Role of Microlayer Evaporation during Elongated Bubble Flow Pattern}

Comparing pool boiling and the microchannel flow boiling processes, the three distinct modes of heat transfer that can be identified in both cases are:

a) Transient conduction heat transfer resulting from the motion of liquid-vapor interface over the heated surface. The heat transfer is enhanced due to the cooler liquid being brought in contact with the heater surface as a result of interface movement.

b) Microconvection heat transfer resulting from the increased convection from the interface movement. It is combined with 
the transient conduction contribution effect described above since it is difficult to identify and isolate their individual effects.

c) Microlayer evaporation resulting from the evaporation of a thin layer of liquid left on the heater by the receding liquid-vapor interface.

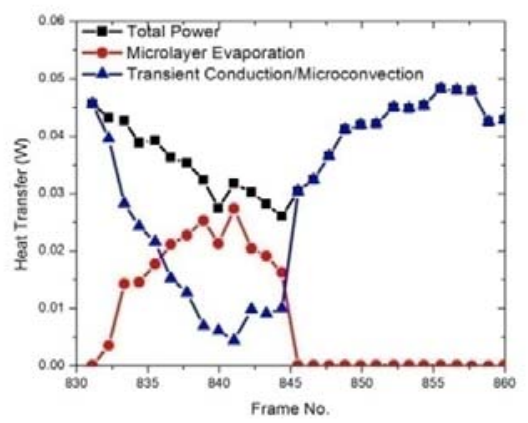

Fig. 8 Relative contributions from different mechanisms during pool boiling. Redrawn using data from Myers et al. (2005).

Relative contributions from these three mechanisms have been a topic of intense research in pool boiling. Myers et al. (2005) used silicon chips with heaters and sensors to determine the localized heat fluxes and surface temperatures around nucleating bubbles. Figure 8 shows the relative contributions from these three mechanisms for water. It can be seen that the transient conduction/microlayer convection together are the largest contributor to the total heat flux during a bubble ebullition cycle. The microlayer contribution was seen to be quite small, around 20 percent. These results are in agreement with the numerical work by Son et al. (1999). Recent work by Moghaddam and Kiger (2009) showed similar results for FC-72.

The microlayer contribution has received considerable attention in recent flow boiling studies in microchannels. It is very difficult to measure the microlayer thicknesss in the microchannel flows. Calculating from the experimental data, a film thickness on the order of $10-20 \mu \mathrm{m}$ has been estimated by Jacobi and Thome (2002) from a parametric study. The initial film thickness was identified as a major parameter, but it was not possible to determine this accurately. Later Thome
(2004) used a thickness of 1-7 $\mu \mathrm{m}$ in his model for R-113 in 200-400 $\mu \mathrm{m}$ channels. Utaka et al. (2003) measured the thickness using a laser absorption technique and reported the thickness in the range 2-34 $\mu \mathrm{m}$. Moriyama and Inoue (1996) reported a film thickness of around $4 \mu \mathrm{m}$ under R-113 bubbles growing in $400 \mu \mathrm{m}$ narrow gaps.

As the film thickness increases, the steadystate equivalent convective coefficient decreases. Figure 9 shows the equivalent convective heat transfer coefficient as a function of film thickness. A $10 \mu \mathrm{m}$ thick water film yields an equivalent coefficient of around $100,000 \mathrm{~W} / \mathrm{m}^{2} \mathrm{~K}$, while $\mathrm{FC}-77$ yields a value around $8,000 \mathrm{~W} / \mathrm{m}^{2} \mathrm{~K}$. Another aspect that needs to be considered is the time it takes to evaporate the film for a given heat flux. It would take approximately $5.2 \mathrm{~ms}$ to evaporate a $10 \mu \mathrm{m}$ film of water under a heat flux of 500 $\mathrm{W} / \mathrm{cm}^{2}$. This corresponds to a frequency of $200 /$ second. The frequencies reported by Dupont et al. (2004) for different fluids backcalculated from their model are between 3 and 90 per second for the relatively lower heat fluxes.

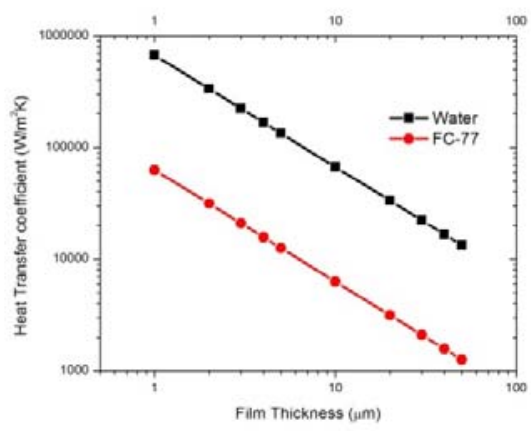

Fig. 9 Equivalent convective coefficient for films under a steady-state conduction model

Actual film thicknesses in flow boiling are found to be much higher. Recent measurements by Zhang et al. (2009) have found the microlayer thickness to be around 10 $\mu \mathrm{m}$ for water in microchannels. The thickness further increases with an increase in flow velocity. Koffman and Plesset, (1983) measured a thickness of 1-3 $\mu \mathrm{m}$ in pool boiling. The microlayer contribution therefore is expected to be lower in microchannel flow boiling because of the increase in the film thickness. 
Table 3 Similarities and Differences between Pool Boiling and Microchannel Flow Boiling Processes

\begin{tabular}{|c|c|c|c|}
\hline Process & Similarities & Pool boiling & Microchannel flow boiling \\
\hline $\begin{array}{l}\text { Nuclea- } \\
\text { tion }\end{array}$ & $\begin{array}{l}\text { The nucleation } \\
\text { criterion by Hsu } \\
(1983) \text { is applicable } \\
\text { for both processes. }\end{array}$ & $\begin{array}{l}\text { Nucleation cavities and } \\
\text { bubble departure sizes are } \\
\text { larger. The low } h \text { in single- } \\
\text { phase prior to nucleation } \\
\text { allows nucleation at lower } \\
\text { wall superheats. }\end{array}$ & $\begin{array}{l}\text { Nucleation cavities and bubble } \\
\text { departure sizes are smaller. The high } h \\
\text { value during single-phase liquid flow } \\
\text { prior to nucleation introduces large wall } \\
\text { superheat. }\end{array}$ \\
\hline $\begin{array}{l}\text { Forces } \\
\text { at iner- } \\
\text { face }\end{array}$ & $\begin{array}{l}\text { Although the forces } \\
\text { responsible } \\
\text { interface movement } \\
\text { are different, transient } \\
\text { conduction r and } \\
\text { microconvection play } \\
\text { a major role. }\end{array}$ & $\begin{array}{l}\text { Gravity (buoyancy), } \\
\text { evaporation momentum and } \\
\text { surface tension forces } \\
\text { dominate. Bubble departure } \\
\text { due to these forces causes } \\
\text { interface movement. }\end{array}$ & $\begin{array}{l}\text { Evaporation momentum, flow inertia } \\
\text { and surface tension determine the nature } \\
\text { of interface movement. Higher flow rate } \\
\text { makes the inertia force dominant (with } \\
\text { similarities to conventional flow } \\
\text { boiling), while higher heat fluxes make } \\
\text { evaporation momentum force dominant. }\end{array}$ \\
\hline $\begin{array}{l}\text { Bubble } \\
\text { growth }\end{array}$ & $\begin{array}{l}\text { Transient conduction } \\
\text { and microconvention } \\
\text { heat transfer processes } \\
\text { are similar. At higher } \\
\text { flow rates, the two- } \\
\text { phase characteristics } \\
\text { of large diameter tubes } \\
\text { appear (such as churn } \\
\text { flow) and } \\
\text { microchannel flow } \\
\text { boiling becomes } \\
\text { distinctly different } \\
\text { from pool boiling. }\end{array}$ & $\begin{array}{l}\text { The bulk liquid is not highly } \\
\text { superheated prior to onset of } \\
\text { nucleation, causing the } \\
\text { bubbles to grow } \\
\text { predominantly near the } \\
\text { heater surface. }\end{array}$ & $\begin{array}{l}\text { Bulk liquid also reaches a high degree } \\
\text { of superheat causing explosive bubble } \\
\text { growth following nucleation. }\end{array}$ \\
\hline $\begin{array}{l}\text { Micro- } \\
\text { layer }\end{array}$ & $\begin{array}{l}\text { Role of microlayer } \\
\text { evaporation is } \\
\text { relatively limited in } \\
\text { both cases, accounting } \\
\text { for only } 20-25 \text { percent } \\
\text { of the total heat } \\
\text { transfer. }\end{array}$ & $\begin{array}{l}\text { The microlayer thickness is } \\
\sim 1-3 \mu \mathrm{m} \text { (Koffman and } \\
\text { Plesset, 1983). The high } \\
\text { frequency in the bubble } \\
\text { ebullition cycle limits the } \\
\text { occurrence, extent and } \\
\text { duration of dry patches from } \\
\text { microlayer depletion from } \\
\text { evaporation at high heat } \\
\text { fluxes. }\end{array}$ & $\begin{array}{l}\text { The microlayer has been measured by } \\
\text { Zhang et al. ( } 2009) \text { to be around } 10 \mu \mathrm{m} \\
\text { for water and has been found to increase } \\
\text { with flow velocity. The frequency of } \\
\text { elongated bubble passage is much lower } \\
\text { compared to pool boiling bubble } \\
\text { departure frequencies. }\end{array}$ \\
\hline $\begin{array}{l}\text { Critical } \\
\text { Heat } \\
\text { Flux }\end{array}$ & $\begin{array}{l}\text { CHF is reached as the } \\
\text { advancing liquid front } \\
\text { is unable to rewet the } \\
\text { dry patches. }\end{array}$ & $\begin{array}{l}\text { Smaller bubbles coalesce } \\
\text { prior to } \mathrm{CHF} \text { as the liquid } \\
\text { interface retracts away. }\end{array}$ & $\begin{array}{l}\text { The dry patches formed during long } \\
\text { duration of elongated bubble flow reach } \\
\text { a high temperature before the arrival of } \\
\text { the liquid front. }\end{array}$ \\
\hline $\begin{array}{l}\text { Heat } \\
\text { transfer } \\
\text { enhance } \\
\text { ment }\end{array}$ & $\begin{array}{lr}\text { Altering } & \text { nucleation } \\
\text { characteristics r will } \\
\text { provide r significant } \\
\text { heat ransfer } \\
\text { enhancements in both } \\
\text { cases. }\end{array}$ & $\begin{array}{l}\text { Providing early nucleation } \\
\text { by introducing cavities of } \\
\text { right sizes and geometries is } \\
\text { successfully implemented in } \\
\text { pool boiling. }\end{array}$ & $\begin{array}{l}\text { Microbubble generation to avoid or } \\
\text { delay formation of large elongated } \\
\text { bubbles may lead to higher heat transfer } \\
\text { rates. Local heating elements driven by } \\
\text { pulsed currents or vibrations may be } \\
\text { used to generate the microbubbles. } \\
\text { Effect of dissolved gases on } \\
\text { microbubble generation and overall } \\
\text { performance needs further study. }\end{array}$ \\
\hline
\end{tabular}




\subsection{Comparison between the Pool Boiling and Microchannel Flow Boiling Processes}

The underlying heat transfer mechanisms in the two processes have many similarities, with transient conduction, microconvection and microlayer evaporation playing similar roles; the essential differences however emerge from the presence of strong inertia forces in the bulk flow in microchannel along with the large shear stress present at the wall. These forces affect the nucleation and other flow and heat transfer characteristics directly.

Table 3 summarizes the main features comparing the two processes. The role of gravity is critical in pool boiling, but this effect is negligible in microchannels, where the interface motion is mainly governed by evaporation momentum and inertia forces. Although the forces are different, the resulting interface movement leads to similarities in the underlying heat transfer mechanisms in the two cases. The effect on critical heat flux is also described, and some enhancement strategies are outlined. Avoiding the thin film dryout and avoiding or delaying the elongated bubble formation are seen as ways to improve the heat transfer and $\mathrm{CHF}$ in microchannels. Microbubbles seem to have great promise in improving the heat transfer. They may be generated in microchannels by using localized heating elements as proposed by Kandlikar (2009b) to stabilize the flow and also lead to an increase in the heat transfer. Introducing vibrations using piezoelectric elements is also seen as a promising technique to generate microbubbles. Although dissolved gases will also lead to generation of microbubbles, their overall effect on the interfacial heat transfer and system performance needs to be investigated. Experimental results from Steinke and Kandlikar (2004) indicate an increase in the subcooled flow boiling heat transfer at the nucleation, but the heat transfer was reduced as the bubbles formed a thin insulating layer. Effective removal of bubbles is important. Further research on these topics is warranted.

\section{CONCLUSIONS}

The similarities between the pool boiling and microchannel flow boiling processes are discussed. The roles of transient conduction, microconvection and microlayer evaporation during elongated bubble flow patterns in microchannel flow boiling are similar to those in pool boiling. Avoiding liquid film dryout, and delaying the formation of elongated bubble flow pattern by introducing microbubbles are proposed as some of the ways to enhance the heat transfer and CHF. As the flow velocity increases, the microchannel flow boiling is expected to resemble the flow boiling in minichannels and conventional sized channels $(>3 \mathrm{~mm})$ with the presence of churn flow pattern. The resulting high pressure drop needs to be considered while operating under such high flow conditions. Shorter flow lengths and improved header arrangements are needed to alleviate the pressure drop limitations. Microbubbles are seen as an effective way to improve heat transfer by avoiding or delaying the formation of elongated bubble flow pattern.

\section{NOMENCLATURE}

\begin{tabular}{ll} 
Bo & Boiling number, $=q^{\prime \prime} /\left(G h_{\mathrm{fg}}\right)$, dimensionless \\
Bo* & Modified Boiling number, defined by eq. (6), \\
dimensionless \\
$\mathrm{D}_{\mathrm{h}} \quad$ Hydraulic diameter, $\mathrm{m}$ \\
$\mathrm{F}_{\mathrm{Fl}} \quad$ Fluid surface parameter, dimensionless \\
$G \quad$ Mass velocity, $\mathrm{kg} / \mathrm{m}^{2}-\mathrm{s}$ \\
$h$ & Heat transfer coefficient, $\mathrm{W} / \mathrm{m}^{2}-\mathrm{K}$ \\
$h_{\mathrm{fg}}$ & Latent heat of vaporization, $\mathrm{J} / \mathrm{kg}$ \\
$q^{\prime \prime}$ & Heat flux, $\mathrm{W} / \mathrm{m}^{2}$ \\
$\mathrm{Re}$ & Reynolds number, dimensionless \\
$x$ & Vapor quality, dimensionless \\
Greek & Letters \\
\hline$\rho$ & Density, $\mathrm{kg} / \mathrm{m}^{3}$ \\
& \\
Subscript \\
$\mathrm{CBD}$ & Convective boiling dominant \\
$\mathrm{G}$ & Gas \\
$\mathrm{L}$ & Liquid \\
$\mathrm{LO}$ & Entire flow as liquid \\
$\mathrm{NBD}$ & Nucleate boiling dominant \\
$\mathrm{TP}$ & Two-phase \\
$\mathrm{V}$ & Vapor
\end{tabular}

\section{REFERENCES}

Colgan, E.G., Furman, B., Gaynes, M., Graham, W., LaBianca, N., Magerlein, J.H., Polastre, R.J., Rothwell, M.B., Bezama, R.J., Choudhary, R., Marston, K., Toy, H., Wakil, J., Zitz, J., Schmidt R., 2007. A Practical Implementation of Silicon Microchannel Coolers for High Power Chips, IEEE Transactions on Components and Packaging Technologies, Vol. 30, pp. 218-225.

Cooper, M.G., 1984. Saturated nucleate pool boiling - a 
simple correlation. 1st UK National Heat Trans. Conf., IChemE Symp. Ser. 86 (2), 785-793.

Das, S.K., Das, P.K., and Saha, P., 2007. Nucleate boiling of water from plain and structured surfaces. Exp. Thermal and Fluid Sci. 31, 967-977.

Dong, T., Yang, Z., Bi, Q., and Zhang, Y., 2008. Freon R141b flow boiling in silicon microchannel heat sinks: Experimental investigation. Heat Mass Tran 44, 315-324.

Dupont, V., Thome, J.R., and Jacobi, A.M., 2004. Heat transfer model for evaporation in microchannels. Part II: comparison with the database. Int. J. Heat Mass Transfer 47, 3387-3401.

Gnielinski, V., 1976. New equations for heat and mass transfer in turbulent pipe and channel flow. Int. Chem. Eng. $16,359-368$.

Hetsroni, G., Mosyak, A., Pogrebnyak, E., and Segal, Z., 2005. Explosive boiling in parallel microchannels. Int. J. of Multiphase Flow. 31, 371-392.

Hsu, Y.Y., 1962. On the size range of active nucleation cavities on a heating surface. ASME J. Heat Transfer 84, 207-216.

Jacobi, A.M., and Thome, J.R., 2002. Heat transfer model for evaporation of elongated bubble flows in microchannels. J. Heat Transfer 124, 1131-1136.

Kandlikar, S. G., 1991, Development of a flow boiling map for subcooled and saturated flow boiling of different fluids inside circular tubes. J. Heat Transfer 113 (1), 190-200.

Kandlikar, S. G., 1990. A general correlation for two-phase flow boiling heat transfer inside horizontal and vertical tubes. J. Heat Transfer, 112 (1), 219-228.

Kandlikar, S.G., 2009a. Scale effects of flow boiling in microchannels: A fundamental perspective. Keynote paper presented at the 7th International Conference on Boiling Heat Transfer, Florianopolis. May 2-7.

Kandlikar, S.G., 2009b. "Methods for Stabilizing Flow in Channels and Systems Thereof," U.S. Patent No. 7,575,046, issued August 2009.

Kandlikar, S.G., and Balasubramanian, P., 2004. An Extension of the Flow Boiling Correlation to Transition, Laminar and Deep Laminar Flows in Minichannels and Microchannels. Heat Transfer Engineering 25 (3), 86-93.

Kandlikar, S. G., Kuan, W. K., and Mukherjee, A., 2005. Experimental study of heat transfer in an evaporating meniscus on a moving heated surface. J. Heat Transfer 127, 244-252.

Kandlikar, S.G., Kuan, K., Willistein, D.A., and Borrelli, J., 2006. Stabilization of flow boiling in microchannels using pressure drop elements and fabricated nucleation sites. J. Heat Transfer 128, 389-396.

Kew, K., and Cornwell, K., 1997. Correlations for prediction of boiling heat transfer in small diameter channels. Applied Thermal Engineering 17, 705-715.

Kenning, D.B.R., and Cooper, M.G., 1988. Saturated Flow Boiling of Water in Vertical Tubes. Int. J. Heat Mass Transfer 31, 445-458.

Koffman, L.D., and Plesset, M.S., 1983. Experimental observations of the microlayer in vapor bubble growth on a heated solid. J. Heat Transfer 105, 625-632.

Kuo, C.-J., and Peles, Y., 2007. Local measurement of flow boiling in structured surface microchannels. Int. J. Heat Mass Transfer 50, 4513-4526.

Kuo, C.-J., and Peles, Y., 2008, Flow boiling instabilities in microchannels and means for mitigation by reentrant cavities. J. Heat Transfer 130, Article No. 072402, 10 pp.
Lazarek, G.M., and Black, S.H., 1982, Evaporative heat transfer, pressure drop and critical heat flux in a small vertical tube with R-113. Int. J. Heat Mass Transfer 25, 945-960.

Moghaddam, S., and Kiger, K., 2009. Physical mechani-sms of heat transfer during single bubble nucleate boiling of FC72 under saturation conditions - I. Experimental investigation. Int. J. Heat Mass Transfer 52, 1284-1294.

Moriyama, K., and Inoue, A., 1996. Thickness of the liquid film formed by a growing bubble in a narrow gap between two horizontal plates. J. Heat Transfer, 118, 132-139.

Mukherjee, A., and Kandlikar, S. G., 2006. Numerical study of an evaporating meniscus on a moving heated surface. J. Heat Transfer 128, 1285-1292.

Mukherjee, A., and Kandlikar, S.G., 2005. Numerical simulation of growth of a vapor bubble during flow boiling in a microchannel. Microfluidics and Nanofluidics 1 (2), 137-145.

Myers, J.G., Yerramilli, V.K., Hussey, S.W., Yee, G.F., and Kim, J., 2005. Time and space resolved wall temperature and heat flux measurements during nucleate boiling with constant heat flux boundary conditions. Int. J. Heat Mass Transfer 48, 2429-2442.

Nukiyama, S., 1934. Original article in J. Soc. Mech. Eng. 37, 367-374. Translation - 1966. The maximum and minimum values of heat $\mathrm{Q}$ transmitted from metal to boiling water under atmospheric pressure. Int. J. Heat Mass Transfer 9, 1419-1433.

Serizawa, A., Feng, Z., and Kawara, Z., 2002. Two-Phase Flow in Microchannels. Experimental Thermal and Fluid Science26, 703-714.

Son, G., Dhir, V.K., and Ramanujapu, N., 1999. Dynamics and heat transfer associated with a single bubble during nucleate boiling on a horizontal surface. J. Heat Transfer 121, 623-629.

Steinke, M. E., and Kandlikar, S. G., 2004. An experimental investigation of flow boiling characteristics of water in parallel microchannels. J. Heat Transfer 126, 518-526.

Steinke, M.E., and Kandlikar, S.G., 2006, "Single-Phase Liquid Heat Transfer in Plain and Enhanced Microchannels," Proceedings of the ASME 4th International Conference on Nanochannels, Microchannels and Minichannels, ICNMM2006, pp. 943-951.

Steinke, M.E., and Kandlikar, S.G., 2004, Control and effect of dissolved air in water during flow boiling in microchannels, Int. J. Heat Mass Transfer, 47, 1925-1935.

Thome, J.R., 2004. Boiling in microchannels. Int. J. Heat and Fluid Flow 255, 128-139.

Utaka, Y., Tasaki, Y., and Okuda, S., 2003. Measurement of micro layer thickness in microchannel vapor generator (in Japanese). In: Proceedings of the 40th national heat transfer symposium of Japan, Hiroshima, Japan, May 2003, vol I, G152.

Zhang, Y., Utaka, Y., Kashiwabara, and Kamiaka, T., 2009. Characteristics of Microlayer Thickness formed During Boiling in Microgaps. ICNMM09-82244, 6pp, ASME Seventh International Conference on Nanochannels, Microchannels and Minichannels, June 22-24, Pohang, Korea.

Zhang, L., Wang, E.N., Goodson, K.E., and Kenny, T.W., 2005. Phase change phenomena in silicon microchannels. Int. J. Heat and Mass Transfer 48, 1572-1582. 